\title{
The role of historical and contemporary processes on phylogeographic structure and genetic diversity in the Northern Cardinal, Cardinalis cardinalis
}

Brian Tilston Smith ${ }^{1,2^{*}}$, Patricia Escalante ${ }^{3}$, Blanca E Hernández Baños ${ }^{4}$, Adolfo G Navarro-Sigüenza ${ }^{4}$, Sievert Rohwer ${ }^{5}$ and John Klicka ${ }^{2}$

\begin{abstract}
Background: Earth history events such as climate change are believed to have played a major role in shaping patterns of genetic structure and diversity in species. However, there is a lag between the time of historical events and the collection of present-day samples that are used to infer contemporary population structure. During this lag phase contemporary processes such as dispersal or non-random mating can erase or reinforce population differences generated by historical events. In this study we evaluate the role of both historical and contemporary processes on the phylogeography of a widespread North American songbird, the Northern Cardinal, Cardinalis cardinalis.
\end{abstract}

Results: Phylogenetic analysis revealed deep mtDNA structure with six lineages across the species' range. Ecological niche models supported the same geographic breaks revealed by the mtDNA. A paleoecological niche model for the Last Glacial Maximum indicated that cardinals underwent a dramatic range reduction in eastern North America, whereas their ranges were more stable in México. In eastern North America cardinals expanded out of glacial refugia, but we found no signature of decreased genetic diversity in areas colonized after the Last Glacial Maximum. Present-day demographic data suggested that population growth across the expansion cline is positively correlated with latitude. We propose that there was no loss of genetic diversity in areas colonized after the Last Glacial Maximum because recent high-levels of gene flow across the region have homogenized genetic diversity in eastern North America.

Conclusion: We show that both deep historical events as well as demographic processes that occurred following these events are critical in shaping genetic pattern and diversity in C. cardinalis. The general implication of our results is that patterns of genetic diversity are best understood when information on species history, ecology, and demography are considered simultaneously.

\section{Background}

A multitude of studies of various North American taxa have shown that historical events, such as Pleistocene climatic changes coupled with topographic, hydrologic and ecological barriers, were instrumental in generating phylogeographic structure within species [1-4]. From the extensive body of phylogeographic work on North

\footnotetext{
* Correspondence: btsmith@unlv.nevada.edu

${ }^{1}$ School of Life Sciences, University of Nevada, Las Vegas, 4505 S. Maryland

Parkway Box 454004 Las Vegas, NV 89154, USA

Full list of author information is available at the end of the article
}

American species, two generalizations have emerged 1) taxa were isolated into independently evolving lineages (i.e. species, subspecies, phylogroups) during the Pleistocene [5] and 2) genetic diversity within species is highest in areas that remained stable (refugia) through glacial cycles [6]. Ultimately, these hypothesized predictions seek to link the phylogeographic structure in species to historical events.

A recent and critical historical event was the Last Glacial Maximum, a time when ice sheets covered much of present-day temperate North America. Entire biotas
C Biomed Central

C 2011 Smith et al; licensee BioMed Central Ltd. This is an Open Access article distributed under the terms of the Creative Commons Attribution License (http://creativecommons.org/licenses/by/2.0), which permits unrestricted use, distribution, and reproduction in any medium, provided the original work is properly cited. 
were fragmented and displaced to more southern latitudes [6]. After the glaciers receded certain species colonized these newly available areas by rapid long-distance dispersal, a phenomenon referred to as the leading edge or pioneer model [7]. A major prediction of the leading edge model is that genetic diversity will be lower in the recently colonized areas. This idea is supported by the observation that many species have higher genetic diversity in European refugial areas [6]. Additionally, genetic data indicate that historical population expansions occurred in many species, a finding consistent with species colonizing newly available areas with suitable habitat. A goal of phylogeography is to recover evidence of population expansions; however, the lag between earlier population expansions and the present represents a time when ongoing demographic processes can either erase earlier genetic signatures of population structure or expansions or prevent such signatures from developing at all.

Contemporary processes can affect the spatial distribution of genetic diversity in various ways. High levels of gene flow may homogenize haplotype diversity throughout a population that once showed genetic structure. Conversely, nonrandom mating with individuals in close geographic proximity can generate genetic structuring within a continuous population [8]. Autecology also plays a critical role in how species maintain genetic connectivity across the landscape $[9,10]$. Vagile species with high ecological thresholds will be able spread haplotypes across an area more readily than poor dispersers with narrow ecological requirements. Interpretations of genetic diversity patterns are further confounded by changes in gene flow due to oscillations in population densities and by shifts in the connectivity of habitats. These points highlight the complexity of population-level processes and emphasize that genetic patterns of diversity may become so tightly coupled to ongoing processes that signatures of historical differences or similarities may be erased.

To examine the impact of historical and contemporary processes on genetic pattern and diversity, we investigated a broadly distributed North American songbird, the Northern Cardinal (Cardinalis cardinalis). Cardinals are distributed from southeastern Canada, throughout the eastern United States, and in the southwestern states south through the Mexican lowlands to northern Central America [11]. Cardinalis cardinalis is currently divided into 18 subspecies representing four subspecies groups [11]. The species inhabits multiple biomes which include deserts, dry and humid tropical forests, and deciduous temperate forests. In all regions it prefers similar habitats of shrubs, small trees, forest-edge, or secondary growth [11].

In this study we use mitochondrial DNA (mtDNA) sequences, ecological niche models, and demographic data to test the impacts of historical and contemporary processes on pattern of present-day genetic differentiation and diversity in C. cardinalis. First, we evaluated whether historical events had generated deep phylogeographic structure or monophyletic groups in mtDNA across the range of cardinals. Second, we tested for the signature of historical demographic expansions that should have been generated in populations that expanded following glacial retreat. Third, we used present-day and paleoecological niche models to explore if clades had geographically stable ranges since the Last Glacial Maximum. Finally, we evaluate if genetic diversity patterns can be explained by contemporary demographic processes.

\section{Results}

\section{Genetic Diversity and Pattern}

The best-fit models of sequence evolution were GTR + I $+\mathrm{G}$ for the complete ND2 gene, GTR + I for the $1^{\text {st }}$ and $2^{\text {nd }}$ codons and GTR $+\mathrm{I}+\mathrm{G}$ for the $3^{\text {rd }}$ codon. Both the partitioned and unpartitioned analyses yielded trees with similar topologies but with different likelihoods. The partitioned dataset $(\operatorname{lnL}-5082.52)$ was a better fit to the data than the unpartitioned data $(\ln \mathrm{L}$ -5354.79) with a $\ln$ Bayes factor of 272.27. Although the harmonic mean method can be sensitive to a high degree of variance [12-14], the Bayes factors reported here are informative because the likelihoods of the two mtDNA gene trees are well separated [15]. The mtDNA tree strongly indicated deep genetic structure across the range of $C$. cardinalis with no mtDNA haplotype sharing among regions except potentially in the Mexican Gulf coast region (Figure 1). Most major nodes in the tree had posterior probabilities greater than 0.95. Exceptions were the node for the cardinalis clade $(\mathrm{pp}<0.50)$ and the lack of reciprocal monophyly between the coccineus and saturatus clades. Uncorrected node to internode genetic distance for each clade ranged from 0.35 $2.60 \%$ (Table 1).

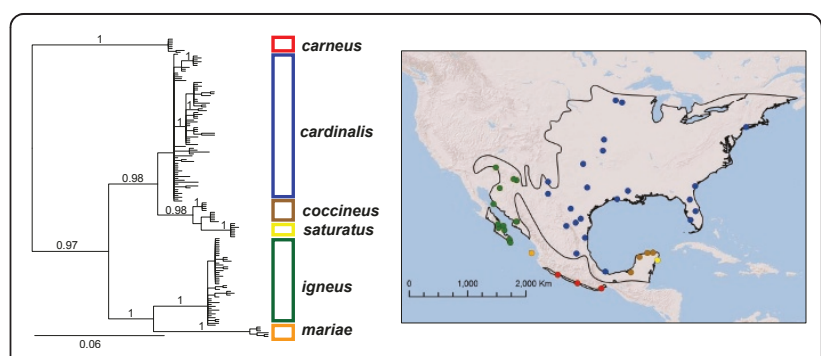

Figure 1 Bayesian mitochondrial gene tree for Cardinalis cardinalis with posterior probabilities. Sampled localities for each clade are plotted on the accompanying map of North America. carneus (red); cardinalis (blue); coccineus (brown); saturatus (yellow); igneus (green); mariae (orange). 
Table 1 Clade genetic and range characteristics

\begin{tabular}{llllllll}
\hline Claudea & Range Size $(\mathbf{s q} \mathbf{k m})$ & $\mathbf{n}$ & Hap & Hap Diversity & $\begin{array}{l}\text { Nuc } \\
\text { Diversity }\end{array}$ & Nuc Diversity* & Genetic Dist \\
\hline cardinalis & $3,189,130$ & 82 & 48 & 0.9530 & 0.00434 & 0.00397 & 0.75 \\
carneus & 35,165 & 8 & 3 & 0.4643 & 0.00065 & 0.00083 & 2.60 \\
coccineus & 204,229 & 11 & 3 & 0.6364 & 0.00175 & 0.00186 & 0.35 \\
igneus & 444,297 & 47 & 21 & 0.8608 & 0.00197 & 0.00179 & 1.65 \\
mariae & 245 & 6 & 2 & 0.7333 & 0.00173 & 0.00173 & 1.65 \\
saturatus & 647 & 8 & 2 & 0.2500 & 0.00024 & 0.00032 & 0.35 \\
\hline
\end{tabular}

Summary of genetic diversity indices and range sizes for the six Cardinalis cardinalis clades. Number of individuals ( $\mathrm{n}$ ). Number of unique haplotypes (Hap). Metric on the proportion of unique haplotypes in a clade (Hap diversity). Nucleotide diversity with complete clade sampling (Nuc Diversity). Nucleotide diversity with equal sampling per clade (Nuc Diversity*). Node to internode genetic distance based uncorrected p-distances (Genetic Dist).

The genetic breaks are largely concordant with the four long-recognized morphological groups: carneus, igneus, coccineus, and cardinalis [11] with the addition of two monophyletic island lineages, saturatus within coccineus and mariae within igneus (Figure 1, Figure 2). Molecular dating from mtDNA indicated that C. cardinalis diverged from the Miocene to Late Pleistocene. The basal split in the mtDNA tree separates the carneus clade from all other cardinals occurred 3.41 million years ago (95\% HPD: 0.99-6.78). The remaining cardinals split into western and eastern clades approximately 2.39 million years ago (95\% HPD: 0.66-4.87). The western clade is comprised of a monophyletic igneus, distributed throughout the Baja California Peninsula, Sonoran and southern Mojave deserts and a monophyletic mariae on the Tres Marías Islands. Mariae diverged from the mainland 1.42 million years ago (95\% HPD: 0.31-2.86). The eastern clade is comprised of three groups (Figure 1). Coccineus occurs on the Yucatán Peninsula and is paraphyletic with respect to the monophyletic saturatus group that occurs only on Cozumel Island. Haplotypes in northeastern México belong to cardinalis, although traditional taxonomy had placed specimens from this region in coccineus. The

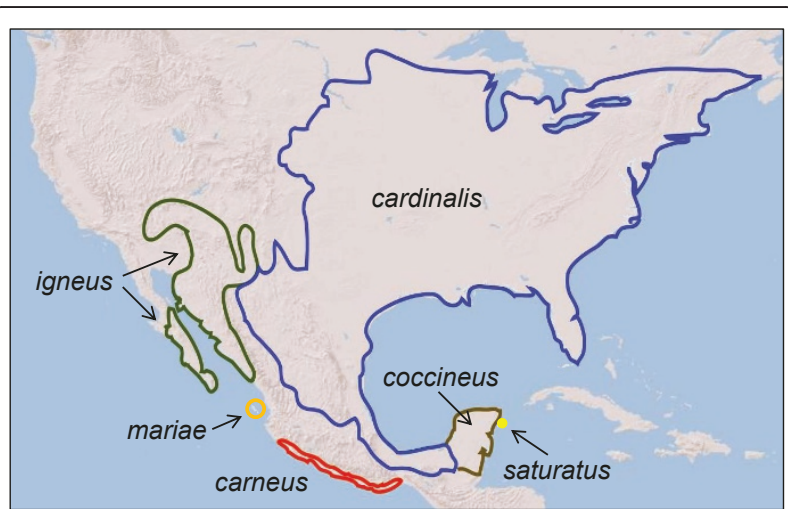

Figure 2 Approximated range limits of the six Cardinalis cardinalis clades based on mtDNA. carneus (red); cardinalis (blue); coccineus (brown); igneus (green); saturatus (yellow); mariae (orange). cardinalis clade is geographically widespread, distributed throughout eastern North America and potentially as far south as Veracruz, México. The first divergence in the eastern clade occurred approximately 1.2 million years ago (95\% HPD: 0.27-0.27) and the second, the divergence of the Cozumel Island cardinals occurred 0.46 million years ago (95\% HPD: 0.07-1.06)

Population genetic analyses revealed differing levels of genetic structure for the two more widespread clades, igneus of northwest México and the southwestern US and cardinalis of eastern North America. In igneus $20.3 \%$ of the genetic variation was among and $79.7 \%$ was within populations (AMOVA, Table 2). There is very little structure in cardinalis with $97.8 \%$ of variation within and $2.2 \%$ among populations (Table 2). Nucleotide diversity within clades ranged from 0.00024 0.00434 (complete clade sampling) and 0.00032 0.00397 (equal sampling; Table 1). Nucleotide diversity within the cardinalis clade ranged from 0.00278 0.00511 and haplotype diversity was high across all geographic localities $0.900-1.000$ (Table 3). The igneus clade had lower nucleotide diversity $(0.00017-0.00368)$ with the lowest diversity in northern part of the range

Table 2 AMOVA summary for the cardinalis and igneus clades

\begin{tabular}{|c|c|c|c|c|}
\hline $\begin{array}{l}\text { Source of } \\
\text { Variation }\end{array}$ & df & ss & $\begin{array}{l}\text { Variance of } \\
\text { Components }\end{array}$ & $\begin{array}{l}\% \text { of } \\
\text { Variation }\end{array}$ \\
\hline \multicolumn{5}{|l|}{ cardinalis } \\
\hline $\begin{array}{l}\text { Among } \\
\text { Populations }\end{array}$ & 8 & 4.537 & 0.011 & 2.19 \\
\hline $\begin{array}{l}\text { Within } \\
\text { Populations }\end{array}$ & 68 & 32.372 & 0.476 & 97.81 \\
\hline Total & 76 & 36.909 & 0.487 & \\
\hline Fixation Index & FST: & 0.022 & p-value & 0.028 \\
\hline \multicolumn{5}{|l|}{ igneus } \\
\hline $\begin{array}{l}\text { Among } \\
\text { Populations }\end{array}$ & 3 & 4.198 & 0.093 & 20.26 \\
\hline $\begin{array}{l}\text { Within } \\
\text { Populations }\end{array}$ & 44 & 16.031 & 0.364 & 79.74 \\
\hline Total & 47 & 20.229 & 0.457 & \\
\hline Fixation Index & FST: & 0.203 & p-value & $<0.000$ \\
\hline
\end{tabular}


Table 3 Within clade genetic diversity

\begin{tabular}{llllll}
\hline Locality & $\begin{array}{l}\text { \# of } \\
\text { Ind }\end{array}$ & $\begin{array}{l}\text { \# of } \\
\text { Hap }\end{array}$ & $\begin{array}{l}\text { Nuc } \\
\text { Div }\end{array}$ & $\begin{array}{l}\text { Hap } \\
\text { Div }\end{array}$ & $\begin{array}{l}\text { Priv } \\
\text { Hap }\end{array}$ \\
\hline $\begin{array}{l}\text { cardinalis } \\
\text { Coahuila }\end{array}$ & 8 & 6 & 0.00278 & 0.929 & 0.50 \\
Florida/Georgia & 9 & 7 & 0.00406 & 0.944 & 0.56 \\
Kansas & 5 & 4 & 0.00462 & 0.900 & 0.40 \\
Louisiana & 9 & 8 & 0.00443 & 0.972 & 0.67 \\
Minnesota/Wisconsin & 9 & 7 & 0.00406 & 0.917 & 0.56 \\
New York & 9 & 8 & 0.00422 & 0.972 & 0.67 \\
Oklahoma & 10 & 7 & 0.00312 & 0.933 & 0.40 \\
Tamaulipas/Nuevo & 8 & 8 & 0.00511 & 1.000 & 0.88 \\
Leon & 12 & 10 & 0.00371 & 0.955 & 0.40 \\
Texas/New Mexico & 12 & & & & \\
& & & & & \\
igneus & 11 & 2 & 0.00017 & 0.182 & 0.00 \\
Arizona/New Mexico & 13 & 9 & 0.00177 & 0.872 & 0.56 \\
Baja California Sur & 13 & 13 & 0.00211 & 0.906 & 0.69 \\
Sinaloa & 19 & 3 & 0.00368 & 0.833 & 0.67 \\
Tiburón Island & 4 & & & & \\
\hline
\end{tabular}

Summary of genetic diversity within the cardinalis and igneus clades. Number of individuals (\# of Ind). Number of haplotypes (\# of Hap). Nucleotide diversity (Nuc Div). Haplotype diversity (Hap Div). Frequency of private haplotypes (Priv Hap).

(Arizona and New México). The pattern of haplotype distributions was low haplotype diversity (0.182) and no private haplotypes in the north (Table 3 ).

For the historical demographic tests, the best-fit substitution model was the same for all three clades (cardinalis, igneus, and coccineus); HKY for $1^{\text {st }}$ and $2^{\text {nd }}$ codon positions and GTR for $3^{\text {rd }}$ codon position. Because igneus shows geographic structure (Table 2), the analysis was run without the Tiburon Island samples (igneus A, Table 4) and a second time without both the Tiburón Island and Baja California samples (igneus B, Table 4). Historical demographic tests for igneus (A and B) and coccineus did not yield robust results because the likelihood values between the constant and expansion growth models were not well-differentiated (Table 4). Lack of evidence for population expansion was further seen in Bayesian skyline plots for igneus and coccineus (Figure $3 \mathrm{~A}$ and $3 \mathrm{~B})$, which were flat across time. In contrast, the Bayesian skyline plot for the cardinalis clade indicated population expansion over time (Figure 3C). The Bayes factors favored the expansion growth model for the cardinalis clade, but given the problems with estimating Bayes factors from the harmonic mean [12-14], the result must be interpreted with caution.

\section{Ecological Niche Models}

Locality records obtained from museum specimens (ORNIS) and field observations (Avian Knowledge Network) indicated that the range of $C$. cardinalis is not continuous (Figure 4A). We constructed separate models
Table 4 Hypothesis testing of historical demography for Northern Cardinal clades using different demographic models

\begin{tabular}{lll}
\hline Model & Marginal Likelihood (S.E.) & log Bayes Factors \\
\hline cardinalis & & - \\
\hline Constant Size & $-2187.800(+/-0.336)$ & 7.520 \\
Expansion Growth & $-2170.486(+/-0.354)$ & 13.896 \\
Bayesian Skyline & $-2155.803(+/-0.411)$ & \\
\hline igneus A & & - \\
\hline Constant Size & $-1585.983(+/-0.316)$ & 2.445 \\
Expansion Growth & $-1580.354(+/-0.350)$ & 9.052 \\
Bayesian Skyline & $-1565.140(+/-0.364)$ & - \\
\hline igneus B & & 0.505 \\
\hline Constant Size & $-1513.415(+/-0.311)$ & 4.494 \\
Expansion Growth & $-1512.251(+/-0.254)$ & \\
Bayesian Skyline & $-1503.067(+/-0.303)$ & - \\
\hline coccineus & & 0.075 \\
\hline Constant Size & $-1380.049(+/-0.174)$ & \\
Expansion growth & $-1380.054(+/-0.166)$ & \\
Bayesian Skyline & $-1379.877(+/-0.170)$ & \\
\hline
\end{tabular}

igneus A - Tiburón Island samples were removed.

igneus B - Baja California and Tiburón Island samples removed

from the four clades with the following number of records; cardinalis $(\mathrm{n}=232)$, carneus $(\mathrm{n}=86)$, igneus $(\mathrm{n}$ $=195)$, and coccineus $(\mathrm{n}=151)$. The ecological niche models produced by MAXENT performed better than random predictions and the area under the receiver operating characteristic (ROC) curve was close to one (AUC > 0.91) for the four mainland clades. Ecological niche models performed well for the two island populations based on the MAXENT diagnostics but the models did not accurately predict the small distributions of the island populations; therefore these models are not presented. The distributions generated from the present-day ecological niche models (Figure 4B) were consistent with the genetic breaks observed in our mtDNA gene tree (Figure 1 ). There was no suitable climatic conditions connecting cardinalis and igneus across west Texas and New Mexico, but the model predicted areas with suitable climatic conditions for cardinalis into the range of igneus. There was a predicted continuous range across the Gulf Coast connecting the cardinalis and coccineus groups, but only with the lowest suitable values projected onto the map (Figure 4B). The northern extent of the pre- $19^{\text {th }}$ century ecological niche models for igneus and cardinalis tightly follows the northern limits of the locaily records specified in the model (Figure 4C).

The paleoecological niche model showed a pronounced reduction in the current range of the cardinalis clade in the eastern half of the U. S. A., which suggested that our samples in Louisiana, the Southeast, eastern México and possibly Texas are from areas that were a 


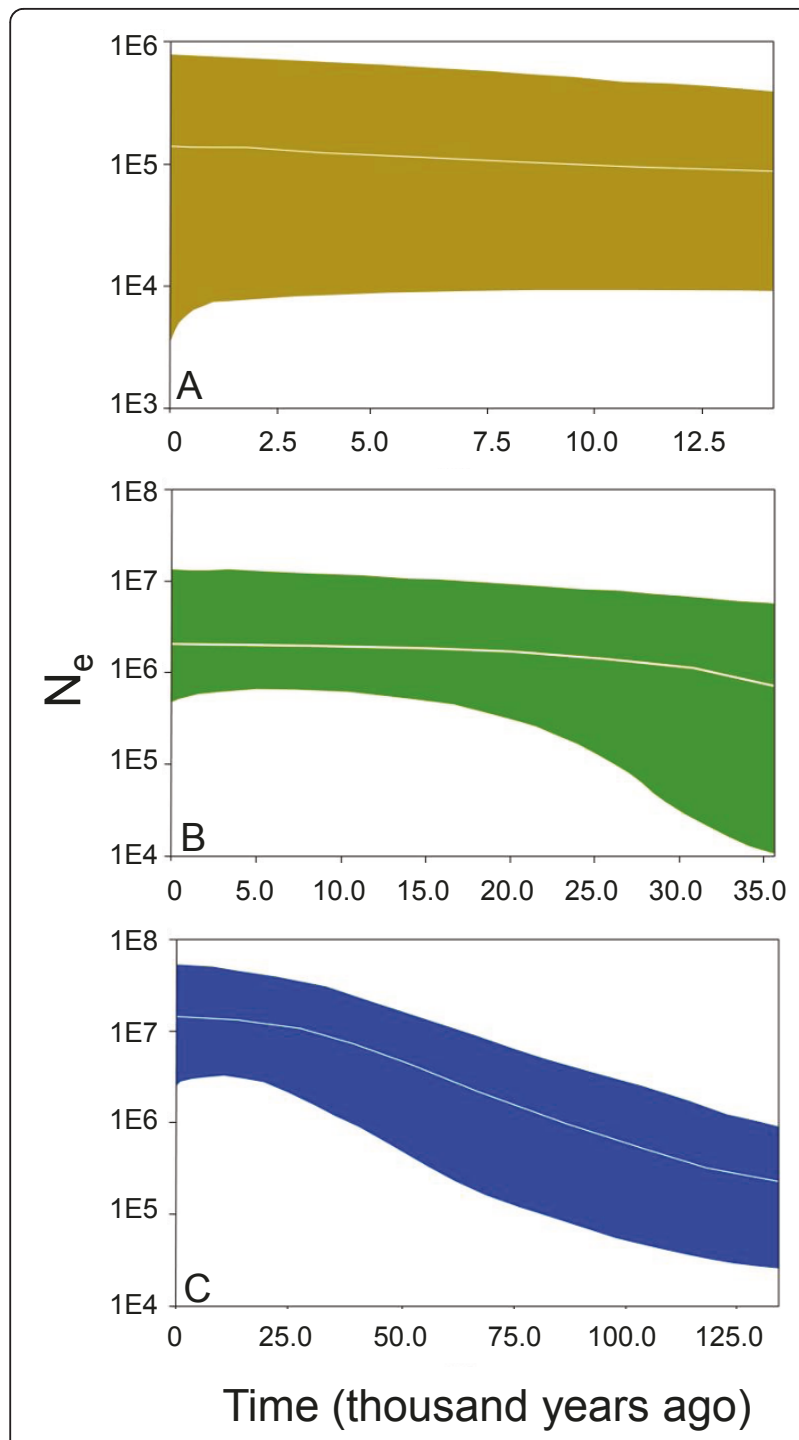

Figure 3 Bayesian Skyline Plots showing change in $N_{e}$ (effective population size) across time in thousands of years. A) coccineus (brown); B) igneus (green); C) cardinalis (blue).

putative refugium (Figure 4D) during the Last Glacial Maximum. The Last Glacial Maximum model also indicated that there were suitable conditions for the cardinalis clade across the Chihuahuan Desert into the Sonoran Desert and east of the Sierra Madre Oriental (Figure 4D). There appears to have been a reduction in suitable climatic conditions for cardinals in México, such as on Baja California and the Mexican Pacific coast, but there was not the extreme range reduction seen in the cardinals of eastern North America.

\section{Spatial and Temporal Correlations}

We found evidence for a positive linear relationship between clade range size and nucleotide diversity (raw values: $\mathrm{R}^{2}=0.83 ; \mathrm{p}=0.01 ; \log$ corrected: $\mathrm{R}^{2}=0.51 ; \mathrm{p}=$

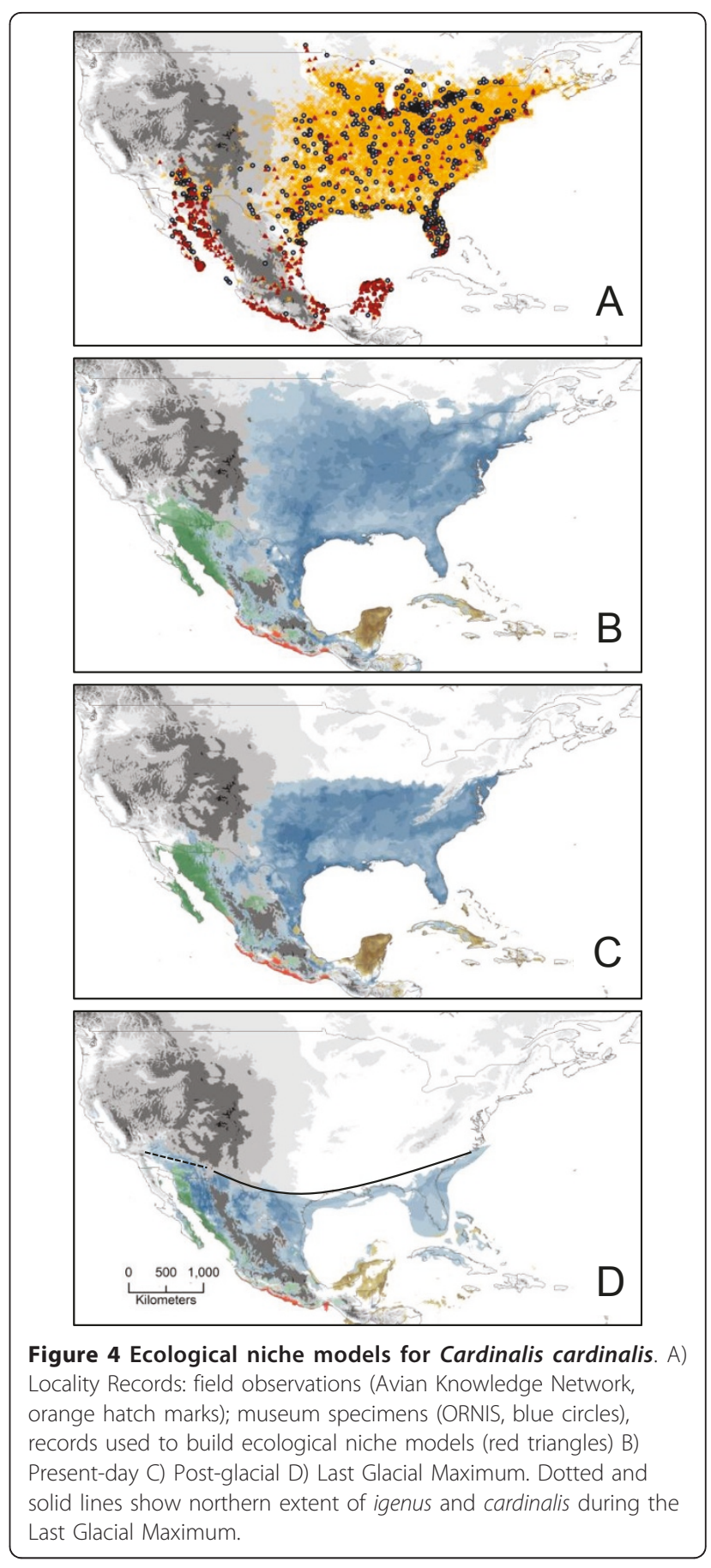

0.11; Table 1). There was no linear relationship between levels of nucleotide diversity and genetic distance $\left(\mathrm{R}^{2}=\right.$ 0.04; $\mathrm{p}=0.69$; Table 1). When we used nucleotide diversity estimates corrected for equal sample size, we obtained qualitatively similar results for the tests on range size and genetic distance. Within the Cardinalis clade neither nucleotide diversity $\left(R^{2}=0.0003 ; p=0.96\right.$; Figure $5 \mathrm{~A})$ or haplotype diversity $\left(\mathrm{R}^{2}=0.25 ; \mathrm{p}=0.17\right.$; Figure $5 B)$ or frequency of private haplotypes $\left(R^{2}=\right.$ 


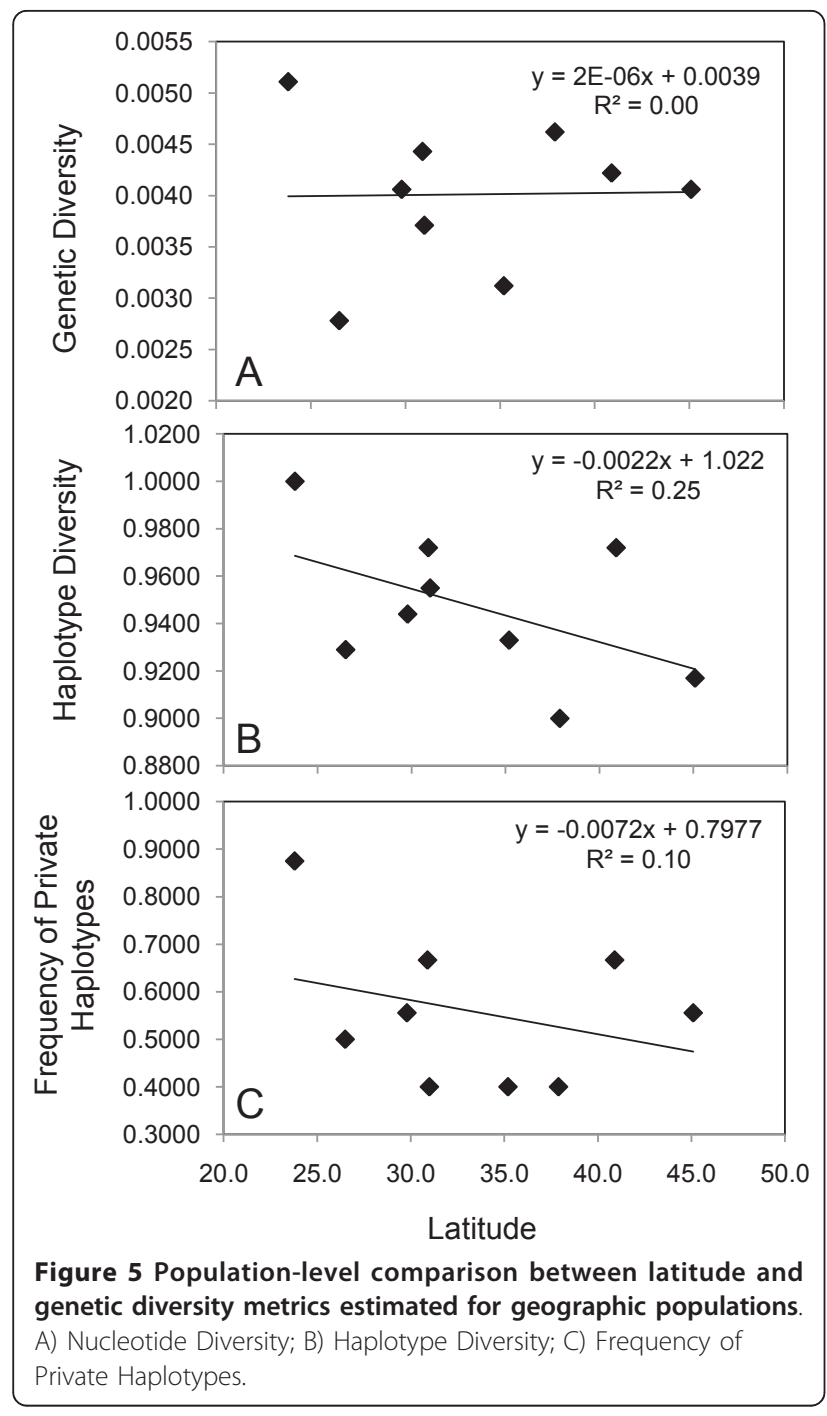

0.097; $\mathrm{p}=0.41$; Figure 5C) exhibited a linear relationship with latitude. However, there was a positive correlation with population growth and latitude $\left(R^{2}=0.690\right.$; $p=0.02$; Figure $6 \mathrm{~B}$ ). This pattern is also seen in contemporary population density estimates, the areas that were stable and colonized in the post-glacial period currently have a density of $30-100$ individuals per area, while areas colonized in the $19^{\text {th }}$ century have $10-30$ individuals per area (Figure 6A).

\section{Discussion}

\section{Historical Signal - Phylogeographic Structure}

Recent historical events, particularly Pleistocene glacialinterglacial cycles, have had a critical impact on generating phylogeographic structure in species [4]. Typically, phylogeographic studies have examined how species responded to these events within a single biome or biogeographic region [16-18]. Here, we report how a
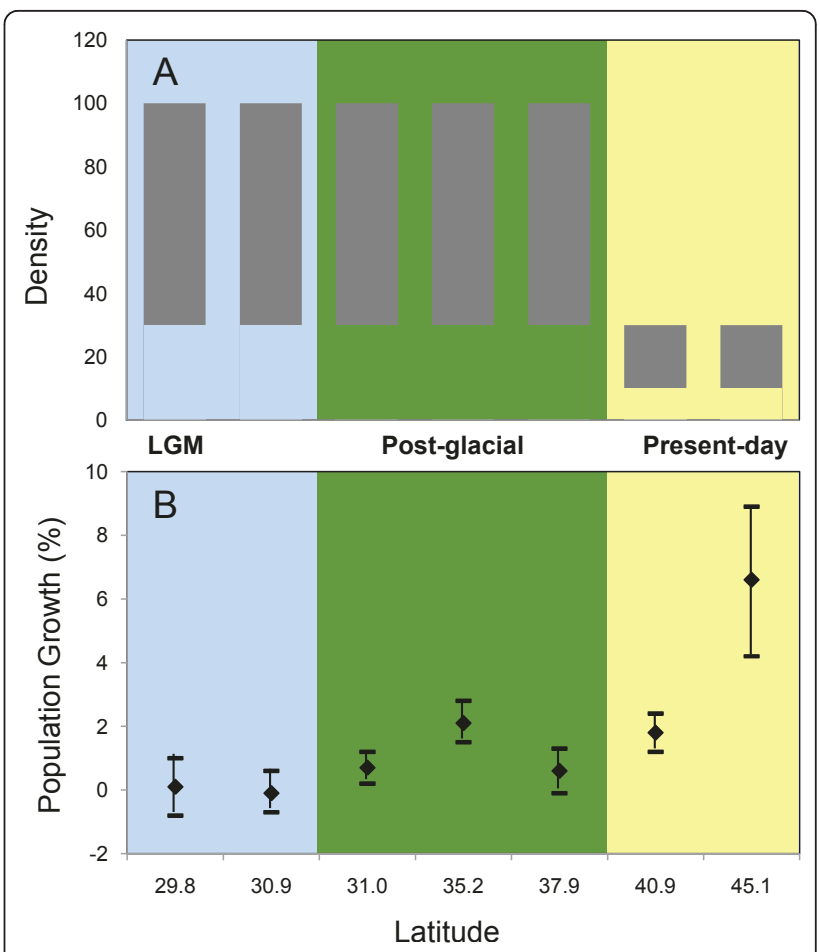

Figure 6 Comparison of contemporary demographic patterns (North American Breeding Bird Survey) across the distribution of the cardinalis clade. Demographic data were obtained for latitudes that had genetic samples included in the study. The colored portions represent latitudes that were inferred from the Ecological Niche Models to be stable since the Last Glacial Maximum (light blue), colonized in the Post-glacial period (green), and colonized since the $19^{\text {th }}$ century, Present-day (yellow). A)

Population density per latitude; B) Population growth (1966-2007 with $95 \%$ Cl) per latitude.

species distributed across multiple biomes and biogeographic regions of North America responded to the climatic oscillations of the Pleistocene. In the Northern Cardinal, we found six lineages that have been likely differentiating since the Pliocene. Each of the four continental clades is found in a well-established biogeographic area: the Mexican Pacific coast, the Sonoran and Peninsular deserts, eastern North America and the Yucatán Peninsula. Additionally, two insular lineages on Cozumel and the Tres Marías Islands were monophyletic.

Major geological and climatic barriers appear to define the ranges of the mainland clades. The distribution of carneus is constrained by the Sierra Madre del Sur to the east and habitat turnover to the north and south. Igenus shares a range with many co-distributed desert species that border the Sierra Madre Occidental to the east and extend to the northern and southern limits of the Sonoran Desert. This clade does not exhibit the deep genetic structure between the Sonoran and Peninsular desert populations found in other co-distributed 
species [19]. However, low-levels of genetic structure were detected in igneus, which is likely due to recent differentiation of the putative subspecies found in the Sonoran Desert, Baja California Peninsula, and Tiburón Island [20]. Present-day gene flow among cardinals in these areas is likely limited by their geographic isolation or by ecological constraints [21], but gene exchange among these groups could have been more regular during the Last Glacial Maximum when sea levels were lower [22] and populations were in closer proximity.

Igneus is replaced in the Chihuahuan Desert by cardinalis and haplotypes of both clades are found east and west of the Chihuahuan-Sonoran transition zone. This region has been identified as an area where many species exhibit genetic breaks and phylogroups often come into secondary contact [4]. Although our sampling was limited in the transition zone, we found no evidence of geographic overlap in these haplotypes and our genetic data and ecological niche model support an earlier conclusion that these forms do not hybridize [20]. The present-day ecological niche model found the geographic area between these clades unsuitable for either group, but the paleoecological niche model indicated a more continuous distribution across this gap during the Last Glacial Maximum.

The evolution of the cardinalis clade in eastern North America has been a history of population connectivity. Remarkably, cardinalis, with a range of over 3,000,000 $\mathrm{km}^{2}$, has no appreciable geographic structure in mtDNA, an unexpected pattern for a widely distributed clade that has several described subspecies. Comparative phylogeographic work on other widely distributed avian species has shown a similar pattern of unstructured mtDNA in eastern North American birds [23]. Alternatively, a diverse array of taxa including birds distributed in the southeast U.S.A. exhibit distinct phylogeographic structure that was shaped by a diverse array of historical factors [1].

The range limits of cardinalis and coccineus in eastern México are not well understood, but the mtDNA break coincides with the biogeographic barrier separating the Yucatán Peninsula biotic province from surrounding regions [24]. Morphological work has identified an area of turnover where cardinalis grades into coccineus in Tamaulipas [25]. Based on genetic data presented, however, specimens from Tamaulipas and areas farther south in Querétaro and Veracruz, México all possessed cardinalis haplotypes. Much of the Gulf Coast along México is unsuitable for cardinals because it has been converted to agriculture or encompasses low-lying areas that periodically flood. The ecological niche model also showed that habitat along the Gulf Coast to be sub-optimal. Additionally, coccineus appears to be a recently diverged lineage and is paraphyletic with respect to the monophyletic saturatus, a pattern consistent with incomplete lineage sorting between young groups [26].

The two island lineages, mariae and saturatus, are currently classified as subspecies in the igneus and coccineus groups, respectively, and both are monophyletic, suggesting that they are independently evolving lineages. Despite Cozumel being only $20 \mathrm{kms}$ from the mainland and remerging 120,000 years ago [27], its biota has become distinct, with eight endemic bird and mammal species. Mariae occurs on the Tres Marías Islands, a small island chain $100 \mathrm{~km}$ off the Pacific coast of México that was likely submerged in the Late Pleistocene [28] and has several endemic subspecies [29]. Molecular dating indicated that the mean mtDNA estimates of these island lineages are "older" than the islands. The divergence of the Tres Marías Islands lineage from the mainland was not congruent with the island's geology; the 95\% HPD (0.31-2.86 million years ago) covers a time period before the island was presumably under water. But, the low end of 95\% HPD for the divergence of the Cozumel Island (0.07-1.06 million years ago) is consistent with geology. The incongruence between the ND2 gene tree and geology may be due to an elevated island substitution rate [30], an undetected time-dependent substitution rate [31], or coalescent variance [32]. Understanding the age of theses island lineages will require more thorough molecular dating using multilocus data.

\section{Mitochondrial DNA as a Phylogeographic Marker}

Mitochondrial DNA is a powerful marker for identifying independently evolving populations within species because of its fast mutation rate and maternal inheritance [33]. However, incomplete lineage sorting [34], rate variation [35], and selection [36] can limit the utility of mtDNA as an evolutionary marker. Overall, the phylogeographic structure presented in this study is largely congruent with the morphological groups previously described for the species. These mtDNA lineages reflect a long history of isolation and independent evolutionary trajectories that merit further evaluation using multilocus coalescent methods [37].

Genetic diversity estimated from mtDNA is impacted by a number of factors, such as population size, age, genetic drift and mutation rate [38]. By using range size and genetic distances as proxies for population size and time of isolation, we were able to show that nucleotide diversity in C. cardinalis was more strongly coupled to range size than genetic distance. This relationship between range size and genetic diversity was expected because larger ranges have the potential for larger populations and thus are able to accrue higher levels of genetic diversity [39]. But, this finding is important because it suggests that mtDNA genetic diversity is at 
least partially coupled with cardinal population size, and indicates that the estimates provided here have not been strongly affected by selection and linkage to the W sex chromosome [40] or genetic draft [41].

\section{Post-glacial Expansion: Historical to Contemporary Demography}

The leading edge model of post-glacial expansion predicts there will be lower genetic diversity in recently colonized regions [7]. Despite strong evidence for this model in some taxa and some geographic areas, there has not been compelling evidence for this pattern in North American birds [[17], [42], [43]; but see [44]]. These results are often attributed to other factors such as mixing of separate refugial populations, un-sampled populations, or rapid expansions. Both our genetic data and our ecological niche modeling suggest a population expansion for the cardinalis.

Given that the cardinalis clade likely expanded out of a glacial refugium, it is surprising that we found nucleotide diversity, haplotype diversity and the frequency of private haplotypes to be uniform across cardinalis sampling localities. Intuitively, homogeneous genetic diversity would seem attributable to birds being more vagile than other vertebrates, but this is unlikely the case here. Many birds are constrained by the same ecological barriers as non-volant organisms [45]. This ecological limitation of dispersal is evident in igneus, which has also undergone a recorded northern range expansion. Our igneus samples from Arizona/ New Mexico had lower haplotype and genetic diversity than samples from Sinaloa. A critical difference between cardinalis and igneus is the amount of habitat connectivity across their ranges. There are few major dispersal barriers for cardinals in eastern North America, allowing the species to freely disperse in any direction. On the other hand, in the areas of the arid Sonoran Desert where cardinals have recently colonized, they are more restricted to habitats with suitable vegetation such as riparian zones.

The high genetic diversity in recently established populations of the eastern cardinalis contradicts the leading edge model and begs explanation. One suggested alternative is the Phalanx model, which posits that large populations expanded slowly into newly available habitats with no loss of genetic diversity in newly colonized areas [7]. Although the Phalanx predicts homogenous genetic diversity as seen in cardinalis, we see no reason for cardinals to have expanded their range slowly. Indeed, the rapid northward range expansion documented in the last 150 years suggests cardinals have high dispersal rates and can rapidly populate suitable habitat. Why may this be the case?

We suggest that cardinals in eastern North America were held at low numbers by a shortage of suitable habitat prior to the European settlement of North
America. Throughout their range cardinals inhabit brushy open habitat, and prior to European settlement this ecotonal species lived in a sea of eastern hardwood forest where suitable habitat was patchy and ephemeral, created by water courses, tree falls, and fires. Throughout most of the evolutionary history of eastern cardinals, suitable habitat must have been ephemeral, leading to selection for high dispersal ability. Once European settlement converted most of Eastern North America into a vast ecotone of excellent cardinal habitat, their evolved propensity for high dispersal would homogenize genetic diversity across vast areas.

The hypothesis that cardinals exhibit high dispersal abilities is borne out by an analysis of banding records for cardinals [46]. Although conducted before root mean square dispersal was being estimated, Dow and Scott [46] found that 190 of 1523 recovered cardinals were found outside the 10-minute block of latitude and longitude where they were banded; among those that moved beyond their block, first years moved an average distance of $60 \mathrm{~km}$ and adults moved an average of 130 $\mathrm{km}$ [11]. These are large distances for a resident bird [47], and comparing them with results for North American blackbirds analyzed in modern ways [48] suggests that root mean square dispersal for Northern Cardinals is very high, possibly exceeding $100 \mathrm{~km}$. Dispersal distances of this magnitude would be sufficient to homogenize genetic variation in a short period of time.

What these data suggest is that during the lag between historical expansion and the present-day, contemporary demography has played a role in shaping the observed genetic diversity pattern. Population densities are lowest at higher latitudes and population growth increases with latitude. We suggest that this population growth is not just from offspring staying in one area and increasing the density of individuals. Instead, populations are also growing as new individuals with different haplotypes are moving into new areas. Given that genetic diversity is uniform even in the youngest cardinal populations, at the highest latitudes, the lag between expansion and genetic homogenization may be on the order of decades instead of hundreds or thousands of years. As new areas became inhabitable, dispersal would likely not have been just in a northern and linear fashion, but east and west. If cardinals expanded out of southern glacial refuges rapidly and in large numbers, the signature of decreased genetic diversity may have been rapidly erased or alternatively, potentially never existed at all.

\section{Conclusions}

In this study we used a widely distributed songbird, the Northern Cardinal, Cardinalis cardinalis, as a model to test historical predictions for how species evolved in response to Pleistocene glacial-interglacial cycles. We 
found evidence in the mitochondrial DNA and from our modeled distribution of the species that there is deep phylogeographic structure in C. cardinalis, which is consistent with fragmentation caused by historical climate change. This structure likely began developing well before the Late Pleistocene and is supported by the results of both contemporary and paleoecological niche models. A modeled paleodistribution along with historical demographic hypothesis tests indicated that cardinals expanded out of refugia in eastern North America since the Last Glacial Maximum. However, there is no signature of decreased genetic diversity in areas colonized after the expansion. We suggest on-going gene flow across eastern North America has likely homogenized genetic diversity across the region. These results demonstrate that both Earth history events and cotemporary processes are important in determining the geography of genetic diversity observed within species.

\section{Methods}

We obtained samples from 163 individuals of Cardinalis cardinalis that includes representatives from 14 of the 18 recognized subspecies and the four subspecies groups: carneus, igneus, coccineus, and cardinalis (Additional file 1 ). We included six closely related species [49] in our dataset; C. sinuatus, C. phoeniceus, Rhodothraupis celaeno, Periporphyrus eyrthromelas, Caryothraustes poliogaster, and C. canadensis) and the more distantly related Molothrus ater as the outgroup. We extracted total genomic DNA from tissues and toe-pads from voucher specimens using the DNeasy tissue extraction kit (Qiagen, Valencia, CA). We amplified the mitochondrial gene NADH dehydrogenase subunit II (ND2) via polymerase chain reaction (PCR) using the primers L5215 [50] and HTrpc (STRI). We used $12.5 \mu \mathrm{l}$ reactions using the following protocol: denaturation at $94^{\circ} \mathrm{C}$ for $10 \mathrm{~min}, 40$ cycles of $94^{\circ} \mathrm{C}$ for $30 \mathrm{~s}, 54^{\circ} \mathrm{C}$ for $45 \mathrm{~s}$, and $72^{\circ} \mathrm{C}$ for $2 \mathrm{~min}$, followed by a final $10 \mathrm{~min}$ elongation at $72^{\circ} \mathrm{C}$. PCR products were sent to High-Throughput Genomics Unit (University of Washington, Seattle) for all subsequent sequencing steps. PCR products were purified using ExoSAP-IT (USB Corporation, Cambridge, MA), run through cycle-sequencing reactions and final products were sequenced using BigDye (Applied Biosystems, Foster City, CA) on a highthroughput capillary sequencer. We aligned chromatograms of the forward and reverse strands in Sequencher 4.9 (GeneCodes Corporation, Ann Arbor, MI) and sequences were translated into amino acids to check for premature stop codons.

\section{Genetic Pattern}

We used several approaches to get an understanding of the distribution of genetic diversity within $C$. cardinalis.
Aligned sequences were run through the program $\mathrm{Mr}$. Modeltest v. 2.3 [51] to estimate an appropriate model of sequence evolution. We determined the sequence evolution model for the complete ND2 gene as well as data partitioned by codon position $\left(1^{\text {st }}\right.$ and $2^{\text {nd }}$ codon positions and $3^{\text {rd }}$ codon position). The best fit sequence model was determined by use of the Akiake Information Criterion (AIC). We constructed a gene tree using the program, MrBayes v. 3.1.2 [52]. We constructed gene trees with the non-partitioned data and partitioned by codon positions. The branch length prior was set to unconstrained with an exponential distribution with the parameter set to 100.0 to avoid artificially long branches [53]. All priors were unlinked for the partitioned data and we ran this analysis for seven million generations and sampled every 1000. We performed diagnostic tests to evaluate mixing and convergence of MCMC chains and the burn-in was determined from visual inspection of the likelihood plots in the program Tracer v 1.5 [54]. To determine which approach was the best fit to the data, we used Bayes factors, computed from the harmonic mean of the non-partitioned and partitioned posterior likelihoods. We estimated divergence times using the program BEAST v. 1. 6. 1 [55] and ran the analyses with a fixed substitution rate of $1.23 \times 10^{-2}$ subs/site/lineage/ million years, a rate estimated relative to the avian " $2 \%$ rule" [56] used for the gene cytochrome-b [see [45]]. We unlinked ND2 codon positions, and used a Yule speciation tree prior and a relaxed uncorrelated molecular clock (lognormal distribution, mean 0.0123, SD = $0.45)$. The analysis was run for 50 million generations and the posterior output was examined in Tracer v 1.5 [54] to assess mixing and convergence of MCMC chains.

\section{Genetic Diversity}

Clades identified from our gene tree were used to estimate the genetic distance (internode to clade node distance) using an uncorrected p-distance for each clade in the program MEGA 4 [57]. Two of the clades, igneus and cardinalis have relatively large ranges and are comprised of several subspecies; therefore we examined the amount of genetic structure within and among subpopulations for each of these clades by performing an AMOVA (Analysis of Molecular Variance) in the program Arlequin v. 3.11 [58]. For the group designation for the AMOVA, we used U. S. states for cardinalis and for igneus we used the regions Baja California Sur, Tiburón Island, Arizona/New Mexico and Sinaloa. We calculated genetic diversity (the average number of nucleotide differences per site between two sequences), haplotype diversity [59], and the frequency of private haplotypes in the program DNAsp v. 5.10 .01 [60] for each clade and for subpopulations that had adequate 
sample sizes $(\mathrm{n} \geq 8)$. Sample sizes among clades were skewed; therefore we estimated nucleotide diversity with all available samples in a clade and with equal samples $(\mathrm{n}=6)$.

\section{Historical Demography}

To perform hypothesis tests on cardinal historical demography, we re-estimated sequence models for each individual clade that had adequate sampling (cardinalis, coccineus, and igneus). We evaluated demographic history in the program BEAST v. 1. 5.4 [55] by comparing the likelihood of three different models for the coalescent tree prior - constant population size, expansion growth, and Bayesian skyline. This approach allowed us to use Bayes factors to test whether a population expansion was more likely than a constant population size [61]. Given that the approach used to estimate Bayes factors in Tracer has been shown to be yield unstable results [12-14], we additionally evaluated demographic history by examining Bayesian skyline plots, which shows a visual representation of population change over time. We used the same parameter settings (except we used a strict molecular clock for this analysis) and MCMC diagnostics as our BEAST divergence time analysis. Bayes factors were calculated by manually summing the tree likelihood and coalescent/skyline columns in the BEAST log file.

\section{Ecological Niche Models}

We downloaded locality records from two online databases, ORNIS (museum records only http://ornisnet.org) and observation records from the Avian Knowledge Network http://www.avianknowledge.net/content and plotted all records to get an estimate of the $C$. cardinalis distribution. To build an ecological niche model for $C$. cardinalis, we used only records from observations and specimens collected for this study. We assumed that these locality records are the most precise because they have been collected in the last ten years. The number of observation records for $C$. cardinalis was heavily skewed towards records in eastern North America where it is a common "backyard" bird. Therefore, we randomly sampled a subset of the records in order to have a more even sampling scheme. In total we compiled 664 records for C. cardinalis.

Beginning in the late $1800 \mathrm{~s}$ a well-documented northward range expansion has been recorded for C. cardinalis in the northern U. S. A. and the Colorado River Basin $[11,62]$. We built additional ecological niche models that attempted to approximate the pre-expansion distribution by making an estimate of their pre- $19^{\text {th }}$ century range. The specific limits of the species' range prior to expansion are not precisely known. Therefore, based on distribution records [11], we used $40^{\circ} \mathrm{N}$ as a conservative and rough estimate of cardinal's pre- $19^{\text {th }}$ century range (post-glacial) in eastern North America and $33^{\circ} \mathrm{N}$ in the southwest U. S. A. All records above these latitudes were not included in the analysis in the post-glacial ecological niche models.

We used the Bioclimatic variables from the WorldClim dataset (v. 1.4) with a resolution of $2.5 \mathrm{~min}$ [63]. Eight of the variables were correlated with other variables $(R>0.90)$; therefore, we used 11 of the 19 temperature and precipitation variables (BIO1, BIO2, BIO5, BIO6, BIO8, BIO9, BIO10, BIO12, BIO13, BIO15 and BIO18). We generated five replicate models for each separate clade identified from our phylogenetic analysis using the maximum entropy algorithm in MAXENT 3.3.3 [64]. The model was then applied to the Model for Interdisciplinary Research on Climate (MIROC) layers to estimate suitable climatic conditions for $C$. cardinalis during the Last Glacial Maximum. We visualized models in the program ArcGIS 9.3 (ESRI Inc., Redlands, CA). Because the distribution of $C$. cardinalis is well known we used a digital range map [65] to set the logistic threshold values for the climatic suitability for each clade and applied these same threshold values to the paleoecological niche models. To calculate range size of each clade, we converted the model raster files into polygons in ArcGIS 9.3 and recorded polygon area in square kilometers.

\section{Contemporary Demography}

To evaluate the impact of contemporary demography on genetic diversity, we used data from the North American Breeding Bird Survey, a long-term demographic study on breeding birds in the USA and Canada [66]. Breeding Bird Survey data is based on mean counts of species along specified routes from these data density and population growth estimates are approximated. The datasets we used were population growth (\% change over time) and population density estimates. We used population growth based on estimates of demographic trends of this species in a U. S. state over 40 years (1966-2007). For population densities, we directly extracted values from the Summer Distribution Map 1994-2003 using the average latitude from our genetic samples.

\section{Additional material}

Additional file 1: Taxon List. List of taxa used for the study, their geographic localities, and GenBank accession numbers.

\section{Acknowledgements}

We thank R. Bryson Jr., J. DaCosta, G. Spellman, J. Batten, C. Tabone, UNLV Systematics Group, T. Monterrubio, J. Chaves, R. Canales, M. Gurrola, J. 
Rodríguez, J. Jaeger, and two anonymous reviewers. The following individuals and institutions provided samples for the study: Paul Sweet and George Barrowclough (American Museum of Natural History), Christopher Witt and Andrew Jones (Museum of Southwest Biology, University of New Mexico), Robert Zink (Bell Museum of Natural History), Sharon Birks ( $U$ of Washington, Burke Museum of Natural History), and Mark Robbins (University of Kansas). This work was partially funded by a UNLV International Studies Scholarship, a UNLV GPSA grant and an American Museum of Natural History Chapman Grant. This study was conducted in accordance with American and Mexican state and federal permits and in compliance with each government's animal research laws.

\section{Author details}

${ }^{1}$ School of Life Sciences, University of Nevada, Las Vegas, 4505 S. Maryland Parkway Box 454004 Las Vegas, NV 89154, USA. ${ }^{2}$ Marjorie Barrick Museum of Natural History, University of Nevada, Las Vegas, 4505 S. Maryland Parkway Box 454012, Las Vegas, NV 89154-4012, USA. ${ }^{3}$ Instituto de Biología, Universidad Nacional Autónoma de México, México, D.F., México. ${ }^{4}$ Museo de Zoología, Facultad de Ciencias, Universidad Nacional Autónoma de México, Apartado Postal 70-399, México DF 04510, México. ${ }^{5}$ Burke Museum and Department of Biology, University of Washington, Seattle, Washington, USA

\section{Authors' contributions}

All authors have read and approved final manuscript. BTS: Designed study, collected samples, generated data, performed analysis, and wrote the paper. PE: Designed study and collected samples. BEHB: Designed study and collected samples. AGNS: Designed study and collected samples. SR: Designed study, collected samples, and wrote the paper. JK: Designed study, collected samples, and wrote the paper.

Received: 15 January 2011 Accepted: 20 May 2011

Published: 20 May 2011

\section{References}

1. Soltis DE, Morris AB, McLachlan JS, Manos PS, Soltis PS: Comparative phylogeography of unglaciated eastern North America. Mol Ecol 2006, 15:4261-4293.

2. Riddle BR, Hafner DJ, Alexander LF: Phylogeography and systematics of the Peromyscus eremicus species group and the historical biogeography of North American warm regional deserts. Mol Phyl Evol 2000, 17:145-160.

3. Zink RM, Kessen AE, Line TV, Blackwell-Rago RC: Comparative phylogeography of some aridland bird species. The Condor 2001, 103:1-10.

4. Swenson NG, Howard DJ: Clustering of contact zones, hybrid zones, and phylogeographic breaks in North America. Am Nat 2005, 166:581-91.

5. Klicka J, Zink RM: The importance of recent ice ages in speciation: a failed paradigm. Science 1997, 277:1666-1669.

6. Hewitt G: The genetic legacy of the Quaternary ice ages. Nature 2000, 405:907-913.

7. Hewitt GM: Some genetic consequences of ice ages, and their role, in divergence and speciation. Biol J Linn Soc 1996, 58:247-276.

8. Slatkin M: Isolation by distance in equilibrium and non-equilibrium populations. Evolution 1993, 47:264-279.

9. Burridge CP, Craw D, Jack DC, King TM, Waters JM: Does fish ecology predict dispersal across a river drainage divide? Evolution 2008, 62:1484-1499.

10. Burney CW, Brumfield RT: Ecology predicts levels of genetic differentiation in Neotropical birds. Am Nat 2009, 174:358-368.

11. Halkin SL, Linville SU: Northern Cardinal (Cardinalis cardinalis) The Birds of North America No 44.Edited by: Poole A, Gill F. The Birds of North America Inc, Philadelphia; 1999:

12. Lartillot N, Philippe $H$ : Computing Bayes factors using thermodynamic integration. Syst Biol 2006, 55:195-207.

13. Wolpert RL, Schmidler SC: a-Stable limit laws for harmonic mean estimators of marginal likelihoods. Department of Statistical Science, Duke University, Durham, NC; 2010, 10-19.

14. Xie W, Lewis PO, Fan Y, Kuo L, Chen MH: Improving marginal likelihood estimation for Bayesian phylogenetic model selection. Syst Biol 2011, 60:150-160.

15. Liu L, Pearl D: Species trees from gene trees: reconstructing Bayesian posterior distributions of a species phylogeny using estimated gene tree distributions. Syst Biol 2007, 56:504-514.
16. Houston D, Shiozawa DK, Riddle BR: Phylogenetic relationships of the western North American cyprinid genus Richardsonius, with an overview of phylogeographic structure. Mol Phyl Evol 2010, 55:259-273.

17. Spellman GM, Klicka J: Testing hypotheses of Pleistocene population history using coalescent simulations: phylogeography of the pygmy nuthatch (Sitta pygmaea). Proc Roy Soc B Biol 2006, 273:3057-3063.

18. Arbeláez-Cortés E, Nyári ÁS, Navarro-Sigüenza AG: The differential effect of lowlands on the phylogeographic pattern of a Mesoamerican montane species (Lepidocolaptes affinis, Aves: Furnariidae). Mol Phyl Evol 2010, 57:658-668.

19. Riddle BR, Hafner DJ, Alexander LF, Jaeger JR: Cryptic vicariance in the historical assembly of a Baja California peninsular desert biota. Proc Natl Acad Sci USA 2000, 97:14438-14443.

20. Ridgway R: The birds of Middle and North America: a descriptive catalogue of the higher groups, genera, species, subspecies of birds known to occur in North America. U S Nat Mus Bull 1901, 1:50.

21. Rojas-Soto OR, Westberg M, Navarro-Sigüenza AG, Zink RM: Genetic and ecological differentiation in the endemic avifauna of Tiburón Island. $J$ Avian Biol 2010, 41:398-406.

22. Clark PU, Mix AC: Ice sheets and sea level of the Last Glacial Maximum. Quat Sci Rev 2002, 21:1-7.

23. Zink RM: Comparative phylogeography in North American birds. Evolution 1996, 50:308-317.

24. Vázquez-Domínguez E, Arita HT: The Yucatan peninsula: biogeographical history 65 million years in the making. Ecography 2010, 33:212-219.

25. Parkes KC: The Northern Cardinals of the Caribbean slope of México, with the description of an additional subspecies from Yucatan. The era of Alan R Phillips: A festschrift Compiler: Dickerman RW Horizon Communications, Albuquegue; 1997.

26. Omland KE, Baker JM, Peters JL: Genetic signatures of intermediate divergence: population history of Old and New World Holarctic ravens (Corvus corax). Mol Ecol 2006, 15:795-808.

27. Spaw RH: Late Pleistocene carbonate bank deposition; Cozumel Island, Quintana Roo, Mexico. Gulf Coast Assoc Geol Soc Trans 2006, 28:601-619.

28. McCloy C, Ingle JC, Barron JA: Neogene stratigraphy, foraminifera,diatoms, and depostional history of Maria Madre Island, Mexico: Evidence of Early Neogene marine conditions in the southern Gulf of California. Marine Micropaleontology 1988, 13:193-212.

29. Stager KE: The avifauna of the Tres Marías Islands, México. The Auk 1957, 74:413-432.

30. Woolfit M, Bromham L: Population size and the rate of molecular evolution on islands. Proc Roy Soc Lond B 2005, 272:2277-2282

31. Ho SYW, Phillips MJ, Cooper A, Drummond AJ: Time dependency of molecular rate estimates and systematic overestimation of recent divergence times. Mol Biol Evol 2005, 22:1561-1568.

32. Peterson $\mathrm{Gl}$, Masel J: Quantitative prediction of molecular clock and $\mathrm{K}_{\mathrm{a}} /$ $\mathrm{K}_{\mathrm{s}}$ at short timescales. Mol Biol Evol 2009, 26:2595-2603.

33. Zink RM, Barrowclough GF: Mitochondrial DNA under siege in avian phylogeography. Mol Ecol 2008, 17:2107-2121.

34. Maddison WP: Gene trees in species trees. Syst Biol 1997, 46:523-536.

35. Arbogast BS, Edwards SV, Wakeley J, Beerli P, Slowinski JB: Estimating divergence times from molecular data on phylogenetic and population genetic timescales. Annu Rev Ecol Syst 2002, 33:707-740.

36. Cheviron ZA, Brumfield RT: Migration-selection balance and local adaptation of mitochondrial haplotypes in Rufous-collared Sparrows (Zonotrichia capensis) along an elevational gradient. Evolution 2009, 63:1593-1605.

37. Leaché AD, Fujita MK: Bayesian species delimitation in west African forest geckos (Hemidactylus fasciatus). Proc Roy Soc B Biol 2010, 277:3071-3077.

38. Avise JC: Phylogeography: The History and Formation of Species. Harvard University Press, Cambridge; 2000

39. Frankham R: Relationships of genetic variation to population size in wildlife. Cons Biol 1996, 10:1500-1508

40. Berlin S, Tomaras D, Charlesworth B: Low mitochondrial variability in birds may indicate Hill-Robertson effects on the W chromosome. Heredity 2007, 99:389-396.

41. Bazin E, Glémin S, Galtier N: Population size does not influence mitochondrial genetic diversity in animals. Science 2006, 312:570-572.

42. Fry AJ, Zink RM: Geographic Analysis of Nucleotide Diversity and Song Sparrow Population History. Mol Ecol 1998, 7:1303-1313. 
43. Milá B, Smith TB, Wayne RK: Speciation and rapid phenotypic differentiation in the yellow-rumped warbler (Dendroica coronata) complex. Mol Ecol 2007, 16:159-173.

44. Milá B, Girman DJ, Kimura M, Smith TB: Genetic evidence for the effect of a post-glacial population expansion on the phylogeography of a North American songbird. Proc Roy Soc B Biol 2000, 267:1033-1040.

45. Smith BT, Klicka J: The profound influence of the Late Pliocene Panamanian uplift on the exchange, diversification, and distribution of New World birds. Ecography 2010, 33:333-342

46. Dow DD, Scott DM: Dispersal and range expansion by the cardinal: an analysis of banding records. Can J Zool 1971, 49:185-198.

47. Paradis E, Baillie SR, Sutherland WJ, Gregory RD: Patterns of natal and breeding dispersal in birds. J Animal Ecol 2002, 67:518-536.

48. Moore WS, Dolbeer RA: The use of banding recovery data to estimate dispersal rates and gene flow in avian species: case studies in redwinged blackbird and common grackle. The Condor 1989, 91:242-253.

49. Klicka J, Burns K, Spellman GM: Defining a monophyletic Cardinalini: A molecular perspective. Mol Phyl Evol 2007, 45:1014-1032

50. Hackett SJ: Molecular phylogenetics and biogeography of tanagers in the genus Ramphocelus (Aves). Mol Phyl Evol 1996, 5:368-382.

51. Nylander J: MrModeltest v 2.32004 [http://www.abc.se/ nylander].

52. Ronquist F, Huelsenbeck JP: MRBAYES 3: Bayesian phylogenetic inference under mixed models. Bioinfor 2003, 19:1572-1574.

53. Brown JM, Hedtke SM, Lemmon AR, Lemmon EM: When trees grow too long: investigating the causes of highly inaccurate Bayesian branch length estimates. Syst Biol 2010, 59:145-161

54. Rambaut A, Drummond AJ: Tracer v 1.5. 2010 [http://beast.bio.ed.ac.uk/].

55. Drummond AJ, Rambaut A: BEAST: Bayesian evolutionary analysis by sampling trees. BMC Evol Biol 2007, 7:e214.

56. Lovette IJ: Mitochondrial dating and mixed support for the " $2 \%$ rule" in birds. Auk 2004, 121:1-6

57. Tamura K, Dudley J, Nei M, Kumar S: MEGA4: Molecular Evolutionary Genetics Analysis (MEGA) software version 4.0. Mol Biol Evol 2007, 24:1596-1599.

58. Excoffier LGL, Schneider S: Arlequin ver. 3.0: An integrated software package for population genetics data analysis. Evol Bioinfor Onl 2005, 1:47-50.

59. Nei M: Molecular Evolutionary Genetics Columbia Univ Press, New York; 1987.

60. Librado P, Rozas J: DnaSP v5: A software for comprehensive analysis of DNA polymorphism data. Bioinfor 2009, 25:1451-1452.

61. Suchard MA, Weiss RE, Sinsheimer JS: Bayesian selection of continuoustime Markov chain evolutionary models. Mol Biol Evol 2001, 18:1001-1013.

62. Monson G, Phillips AR: Annotated checklist of birds of Arizona. 2 edition. Univ of Arizona Press, Tucson; 1981.

63. Hijmans RJ, Cameron SE, Parra JL, Jones PG, Jarvis A: Very high resolution interpolated climate surfaces for global land areas. Int J Clim 2005, 25:1965-1978.

64. Phillips SJ, Anderson RP, Schapire RE: Maximum entropy modeling of species geographic distributions. Ecol Mod 2006, 190:231-259.

65. Ridgely RS, Allnutt TF, Brooks T, McNicol DK, Mehlman DW, Young BE, Zook JR: Digital Distribution Maps of the Birds of the Western Hemisphere, version 3.0. NatureServe, Arlington 2007.

66. Sauer JR, Hines JE, Fallon J: The North American Breeding Bird Survey, Results and Analysis 1966-2007. Version 5.15 USGS Patuxent Wildlife Research Center, Laurel, MD.

\section{Submit your next manuscript to BioMed Central and take full advantage of:}

- Convenient online submission

- Thorough peer review

- No space constraints or color figure charges

- Immediate publication on acceptance

- Inclusion in PubMed, CAS, Scopus and Google Scholar

- Research which is freely available for redistribution

Submit your manuscript at www.biomedcentral.com/submit
C) Biomed Central 